\title{
Numerological Phraseological Units in Multi-structural Languages
}

\author{
Rauan Dossymbekova (Corresponding author) \\ Al-Farabi Kazakh National University, Almaty, Kazakhstan \\ E-mail: rauan-d@mail.ru \\ Tolkyn Kalibekuly \\ Ablaykhan Kazakh University of International Relations and World Languages. Almaty, Kazakhstan \\ Farida Orazakynkyzy \\ Institute of Multilingual Education, Abai Kazakh National Pedagogical University, Almaty, Kazakhstan \\ Dina Andabayeva \\ Oriental Studies Faculty, Al-Farabi Kazakh National University, Almaty, Kazakhstan \\ Nurkassym Ashimbay \\ Kazakh-Chinese College. Almaty, Kazakhstan
}

Received: 18-05-2016

Published: 01-11-2016
Accepted: 09-08-2016

doi:10.7575/aiac.ijalel.v.5n.6p.141
Advance Access Published: September 2016

URL: http://dx.doi.org/10.7575/aiac.ijalel.v.5n.6p.141

\begin{abstract}
This paper is devoted to the comparative-semantic analysis of numerological phraseological units (PU) in the unrelated languages, namely, Kazakh and English. The identification of the similarities and differences of fixed collocations of multiple languages is a spread type of comparative analysis in phraseology. The possibility of verbalization of the natural environment and man-made environment of ethnic group becomes apparent in comparative studies and description of any lexical-semantic groups of two or more languages. In our work we consider lexical-semantic group of numbers category in Kazakh and English. Numerals are actively involved in the formation of PU, thereby forming a large reservoir of numerological PU and deserve a special consideration. The work is ethnolinguistic and linguoculturological description of the main vernacular numerals, included in the set phrases of the languages. Main methods of the research are: method of semantic analysis, descriptive method, comparative analysis, method of sampling.
\end{abstract}

Keywords: cultural linguistics, contrastive linguistics, phraseology, numerological symbolism, numeral

\section{Introduction}

This work is implemented on the base of the theory of cultural linguistics and is devoted to the comparative-semantic analysis of set phrases with a numeral component, the study of their symbolic significance and cultural identity in unrelated languages, namely, Kazakh and English.

Since ancient times numbers served as means of describing the world order and orientation of a human in it, people attributed the numbers the hidden meanings and magical ability to influence on everything around. Numbers were considered as an integral part of all creatures and objects in the world: they managed physical harmony and laws of life, space and time, the relationship with God, which was understood as the unity of the world, the Supreme Truth. The numbers were interpreted as divine symbols of the universe, the basis of representation of the universe, a symbol of harmony and order opposed to chaos (Toporov, 1988).

The relevance of the problem is due to the interest of modern linguistics to the problem of reflection in language conceptual and value components of the objective world. Verbal representation of real-world objects in a particular culture includes profiles of linguocultural specifics of national language. Important element of conceptual system of human thought is the concept of numbers. In this sense the study of number symbolism is important in determining the characteristics of the world outlook of the considered linguistic cultures. In addition, number as one of the constants of world culture is logical and cultural phenomenon, research of numbers in every national language and ethnic culture will reveal its conceptual characteristics and features and define the relationship between language and culture. Numbers contain rich cultural semantics, they have sacred symbolics. The necessity for comprehensive study of national and cultural symbolics of numbers in the languages determines the relevance of this article. 
The term "symbolics of number" in our work means national and cultural semantics of language units with numeral component. Numerals are considered in our work not only as a unit of language, but also as a cultural unit, reflecting spiritual and material culture, mythological and cosmological ideas, beliefs, customs and rituals of investigated linguocultures.

The goal of the research is linguocultural analysis of numerals in investigated languages. Lexical units with a component of number, collected from defining dictionaries, phrase books and idioglossaries served as the material for the study.

\section{Methods}

Methods and techniques of the research. We used a complex method of analysis, including:

1) method of semantic analysis involves the analysis of cultural values of the numbers;

2) descriptive method comprises monitoring and classification of the material;

3) comparative analysis identifies the universal and distinctive features of numerals in unrelated languages;

4)method of sampling from different phraseological, defining, bilingual dictionaries by the criterion of existence of the numeral component in the linguistic unit.

Theoretical and methodological basis of the study consists of the works of local and foreign experts in the field of philology (Weisgerber, Apresyan, Akulenko); cultural linguistics (Stepanov,Wierzbicka); philosophy (Jespersen, Heidegger and others). The theoretical position of the relationship of language and culture, the principles of linguistic science in the study of culture as holistic phenomenon and as a value-semantic world of a human is defined in the mentioned works. A special role in determining the methodological foundations of this study belongs to the fundamental works of linguists theorists Humboldt, Sapir, Toporov.

\section{Results}

Numbers in Kazakh and English languages are universal symbols of the world culture, on the one hand, and have national and cultural semantics, on the other. Comparative-semantic analysis of fixed combinations of the languages in frames of the study of categories of numbers gives ground to assume that the original premise of the ethnic identity of these expressions in the lexicon of Kazakh and English languages is supported by a large factual material.

Numbers $1,2,3,4,5,7,9,12,40$ are nationally and culturally marked, forming part of the ethnic picture of the world. This is due to the fact that not all the numbers acquire nominal value, but only some of them. The most productive in symbolization are first ten numerals. With the increasing complexity of the morphological structure of the numerals decreases the activity of their use, as evidenced by the limited amount of compound numerals with national and cultural semantics.

Numerals are actively involved in the formation of PU, thereby forming a large phraseological layer. The analysis of phraseology with numeral component in compared languages reveals relatively wide blocks of PU linked by common content and reflecting the conceptual, substantive similarity of designated phenomena.

Comparative study of special group of sacred numbers makes it possible to trace the history of formation and development of the world view, comprehension of reality, and factors of formation and use of fixed units in the vocabulary of people - native speakers.

Detailed multifaceted study and understanding the depth of fixed units of two different languages at the lexicalsemantic, structural-semantic, and cultural levels helps to avoid making a common mistake in translating phraseological units that will arise in proper practical application. Some of the common mistakes are direct translation, which gives a new meaning to the components of the translated combination; improper reinterpretation; and intralingual interference.

Modern linguists investigate the number not only as a grammatical category, but as a fragment of linguistic worldimage. Interest to the study of sacred numbers, their ethnocultural symbols, numerical model of the world of a nation is growing.

Numerals take a special place in cognitive process. Along with the nominative function numerals implement cognitive function, i.e., the ability to reflect main stages of objective knowledge of quantitative relationships. Consequently, numerals may refer to one of the most ancient layers of vocabulary of any language. Universal feature of different languages' numerals is their stepped development from subject to a quantitative value.

In this paper we try to consider so-called sacred (magical) numbers, which penetrated into depths of consciousness of a particular culture representatives and influenced on their way of thinking, their attitude to many facts and phenomena. The essence of such numbers is often perceived instinctively. As conceptual universals in terms of category of number they evolve in a specific cultural environment, are associated with certain customs, traditions, rituals and symbols that make up the national identity of nation.

Kazakh language has quantitative lexicon with prominent culturological significance. For instance, zhalgyz, rising to the numeral one. According to folklore, Kazakhs understood the whole world in binary relationships, harmony and complementarity. Individuality evoked a negative attitude and in national understanding it was inherent only to God (zhalgyzdyq qudaiga gana zharasady - Loneliness can be inherent only to God).

In contrast egiz - twins, zhup - even number in addition to the nominative value represent only positive meaning: fertility, prosperity and development. 
The idea of pairing is reflected in the beliefs of Kazakh people: Kazakh will not cut trees growing in pair, because of the fear that someone will lose his/her partner or relative, or get a curse. Everything on the Earth is created to have its half, and one will get damnation in case of destroying one element of a pair. The perpetrator of such a crime for the rest of life will suffer in anxiety, anguish and despondency (Karabayuly, Bopayuly, 1998).

Most numerals of modern English have their origin from the Old English period. The numeral one is not designated in the counting system and calculus starts with two or more.

As it was noted previously, the counting system of any nation has an anthropocentric motivation, most of the operating systems today are the result of long historical development dating back to the archaic calculus on fingers. Etymological study of the number five is not accidental in English language. The study has led to the fact that it comes from the hand, five fingers: Old English finger, Hittite pankur - whole.

In the ancient Indo-European tradition some numbers acquired a special symbolic meaning, for example, such numbers as 2, 3, 4, 7, 12 (Gamkrelidze, 1984).

Number two reflects the binary opposition of the universe: heaven and earth, day and night, man and woman, etc. Number three in the representations of ancient Europeans also had a sacred significance and was often determined by the amount of main ritually important mythological characters: triceps monsters and entities who engaged in mortal combat with them etc. The sacred value of the three can be seen as a universal phenomenon, inherent in almost all nations. It has a symbolic value integrity, unity: the trinity model of the world, three heroes, etc.

The prevalence of the symbolic value of the number three is also confirmed by the fact that almost in all tales of different nation's heroes trial is performed up to three times.

After seeing a bad dream at night, in the morning Kazakhs spit on the ground three times saying the words tus tulkinin bogy - dream - is fox dungs, and press a sole with a right leg three times and rub the spit. It is a belief that in this case earth will swallow the black sleep.

There is a proverb in English: when three know it, all know it. In addition, it is known that in many rituals the number three is endowed with special significance: names the intending spouses in church are announced three times (to find out if there are any impediments to the marriage), in many countries with Christian religion in the case of joyful events people present to each other an odd number of flowers - three, five, seven, etc.). In UK, a girl is allowed to marry without parents' permission by the age of twenty-one (three times seven).

Particular attitude to the cardinal directions is expressed in Turkic mythology: dunienyn tort buryshy (4 parts of the world), tort kubylasy ten. Apparently, the number four is based on the symbolic meaning of equality. The symbolism of the number four is also pronounced in the Indo-European mythology as mythological images of the four winds are related to the four cardinal points. In addition, this number, as any square one is considered as a symbol of justice. Perhaps this can be explained by the emergence in English language such expressions as fair and square: I will promise you one thing - that we fight you fair and square, with everything open and above board - «I promise you one thing: we will fight fair and open» (Cronin A.J. The Northern Light.P.1, ch.5.)

In Kazakh culture number seven has a special significance and etymological investigations indicate its practical framework. Initially, the root of the morpheme zhety - seven originally meant a finger to eat and hold. (Ramstedt, 1957).

Seven has pronounced symbolic significance in the world view of Kazakhs. Primarily, it is due to the genealogical differentiation: Kazakhs follow the tradition of 7 generations system. According to this system kinship is weakening after the seventh generation, i.e. up to the seventh generation relatives are considered to be close, after the seventh - are distantly related. These social and cultural features of Kazakhs are reflected in number of phraseological units: zheti atasyn bilu- know seven ancestors (according to the tradition self-respecting Kazakh should know his/her seven ancestors by name), zheti atasynan tuk kormegen - to learn nothing from seven great-grandfathers; to be rude, zheti atasynan kelgen bailyq - wealth, inherited from the seven great-grandfathers, family wealth, zheti atasynan qongan aqyndyq - poetic gift, inherited from the seven ancestors, zheti atadan ary qyzalysu - take a bride from relatives after the seventh generation (Kazakhs were forbidden to marry to cousins up to the seventh generation), and others.

In addition, seven is also related to the understanding of religious construction of the universe: zheti qabat zherdin asty - seven-storey underground, aspannyn zheti qabaty - seven-storey heaven. Seven is also connected with rituals: conducting seven-day memorial after somebody's death, seven baked cakes, etc (Husain; Islam, 2004).

One of the belief of ancient Turkic people is seven woes, seven bad lucks:

1. Qurgaqshylyk-drought.

2. Zhut - loss of livestock.

3. Oba-epidemic.

4. Ort-fire.

5. Sogys-war.

6. Sel-mudflow.

7. Zhersilkinu - earthquake. 
Another belief is about seven qualities or virtues, which are characteristic features of a horseman (Kazakh zhigit):

1. Tazy zhuiryk - hound dog.

2. Qyranburkit - clever and powerful eagle.

3. Beren myltyq - good steel gun.

4. Sulu qyz / ayel - beautiful girl / wife.

5. Zhuirykat-racehorse.

6. Er zhigit - a brave boy.

7. Bilim-ilim - science and knowledge.

These features are frequently seen elements in epic tales of Turkic nations.

Seven, according to the beliefs of Kazakhs, can act as a kind of talisman, a savior, a cleaner. For example, "if a dog is howling with its face up to the sky - it is not good: it means that death of the house owner is close. This dog should be cursed with words: Let the misfortune perish and go with you! The dog should be killed after and buried in deep hole of the ground. Seven people press down the grave with a large black stone and, spitting, lam away. There is a belief that this ritual will help to avoid the trouble, and misery will die with the dog in the ground". (Karabayuly, Bopayuly, 1998)

Names of British fairy tales and images also show the symbolic meaning and the ancient origins of the numeral seven: seven seas - all seven oceans of the world, seven sisters - Seven Sisters - astronomical - a cluster of stars in the constellation of Pleiads, the seven deadly sins - according to the Christian tradition of seven basic human sins - pride, greed, lust, anger, gluttony, envy and sloth, seventh-day-Adventist - member of the Protestant sects, preaching Christ's return unto the land, seven wonders - seven wonders of the world, seven most beautiful creations of ancient world, the sevens heaven - heaven, paradise, seven sleepers - an ancient Christian legend of seven young nobles Christians and Ephesus, who escaped the punishment of Desian and slept in a cave for 187 years, seven sages - seven wise men of Greece (Bias, Philon, Cleobulus, Periander, Pitak, Solon, Thales), who, according to Plato are the basic founders of morality school.

Along with this, in English, number seven can mean simply a large number of, not by chance the following expression has two options with the numeral seven, forty-second and pronoun several: cousin seven / several / times removed distant cousin; forty-second cousin - distant cousin (Taylor, 1989).

In the US, number seven is considered to be lucky. Astronauts included number seven in names of each spacecraft: Fait 7 (fate-7), Carpenter 7 (Aurora - 7), etc.

The symbolism of number eight is interpreted differently in many nations. In European culture, in particular ancient Greece, eight - is a symbol of death. Not coincidentally, their kings could rule the state no more than eight years. The Chinese number eight symbolizes life, happiness, well-being, which is probably due to the Buddhist concepts of eternity, infinity, reflected in its graphic image (Parkhamovich, 2011).

According to Ramstedt, Turkic word toguz - nine is associated with the Mongolian toqur/tokir - inflexible fingers (Kazakh dokir - rude, ignorant, awkward origins from it) (Ramstedt G.I., 1957).

Kazakh togyz - nine is often used in a variety of expressions, which came from ancient times and reflect long-forgotten customs and traditions. In old days, in accordance with the degree of litigation between tribes or crime committed by an individual, different ransoms were determined: birtogyz (one nine), ushtogyz (three nines), togyztogyz (nine nines), togyzkesu (overlay fine-togyz). In Kazakh law toguz as a penalty for all serious crimes except murder, was differentiated by multiplying by 3 and 9 .

Crossroads in Kazakh fairy tales are expressed in intersection of nine roads - togyz zholdyn toraby. A similar understanding is inherent to all Turkic people. A lot of Kazakh national ethnographisms were created on the basis of numerals: tuye basy togyz (nine starting with a camel), zhamby bastagan togyz (nine starting with Jamba) - varieties of gifts, consisting of nine elements - items and pets.

It should be noted that the numeral nine among Kazakhs had some superstitious negative meaning. In some areas Kazakhs believed in togyz tergeydi (test with nine). It is a belief that number nine does not bring happiness, and, therefore, on the ninth, nineteenth and twenty-ninth day of each month before noon Kazakhs do not start a new business and they don't set off for journey. The reason for this superstition is difficult to explain and requires a special study (Mashanov. Bizakov, 1968).

English nine is associated with Indo-European neue - new, i.e. new number after a certain cycle, ending with eight.

Despite the fact that European culture is common for British, the sacredness of this number was hardly reflected in language facts.

Number ten in many nations is connected with the concept of decimal notation and symbolizes harmony, completeness, perfection. In addition, the tenth of a unit was a measurement tribute of sacrifice to God. The mythological representations of ten - complete cycle, milestone.

We should emphasis the numeral forty among the sacred values of numbers. Concerning the etymology of Kazakh qyryq - forty among scholars there is no consensus. Kazakh culture attaches value to the rituals of forty days after the birth and death, washing the newborn child for forty days in water of forty spoons. Number forty is very common in 
oriental motives of folk tales, legends, proverbs: hannyn qyryq uaziri bolypty - Khan had forty viziers; qyryq qyz, qyryq zhigit - forty girls and forty horsemen; qyryq kun zhol zhuripti - forty days was in a way; qyryq qazannyn qulagyn tistegen qydyrma - someone who has seen a lot; otyz kun oiyn, qyryq kun toiyn oynady - fun and feast for forty days; zhaqsy ake zhaman balaga qyryq zhylazyq bolady - bad son will live forty years with name of a good father; uyinen qyryq qadam shyqqan adam - zholaushy - forty paces away from home make you a traveler, qyzga qyryq uiden tyim a girl has a lot that is forbidden for her (Kaydar, 2003).

In English phraseological fund examples with forty are rare, and they all express a neutral value.

In European mythology, the number twelve, or a dozen is very common: twelve-headed snakes, twelve brothersrobbers. The word dozen was borrowed in the Middle English period from Latin via French: a baker's dozen, devil's dozen, long dozen. According to an old English custom, merchants received bread from the bakers who feared punishment for underweight; they received thirteen loaves instead of twelve, and the thirteenth one was in the traders' income, and that is how the expression baker's dozen appeared.

Idiom devil's dozen was motivated by medieval superstition of Christians about the number of witches on Sabbath. Dozen comes from the numeral duo - two and dosim - ten, which were formed by compounding at first, and then formed a simplification word for twelve. Around dozen - exactly a dozen.

The symbolism of the number twelve is primarily associated with basic concepts and measurements of astronomy and astrology in western and eastern nations. Moreover, in Christianity the number has a meaning of "the chosen number", which is confirmed by the presence of this amount among the apostles of Jesus Christ, sons of Iyakov, the tribes of Israel, twelve Olympian gods in Greek Pantheon, etc. (Colson, 2005).

In accordance with Hittite and Anatolian traditions, it is believed that twelve is the number of main parts of the sacrificial animal body. It is cut into twelve parts during the religious ritual. (Compare in Kazakh language: maldyn on eki mushesi - 12 parts of an animal). This corresponds to twelve enemies of soul in Old Islamic medical texts. In the early period of ancient Greece, twelve was the main number of the gods. This sacred value of number twelve apparently was due to the division of year into twelve months in Indo-European culture.

The number thirteen in understanding of many people -is unlucky number, which does not bring good luck and is called devil's dozen. The reason for this is in two things: the first is associated with nature, its astronomical laws, and the second - with religion. Early lunar calendars because of its inaccuracy were in need of adding one month, which, according to the belief, brought bad luck. On the other hand, in the rites of witches Satan was thirteenth. From this we can conclude that the symbolism of number thirteen is more common in European than in Asian nations.

And in today's world there is still a belief in negative power of number thirteen. For example, in England, many ships do not leave the harbor on the 13th, believing that it will save them from storms. This superstition is also reflected in the numbering of hotel rooms and cabins: there is fourteenth after the twelfth. In 1930, several thousands of Londoners petitioned the municipality with a request to remove all thirteen rooms from the houses.

Some idioms with numeral as a component is difficult to explain in terms of the origin, as their lexical composition, firstly, is not stable, and secondly, their value is not associated with any custom, tradition or belief: for example, talk nineteen (twenty or forty) to the dozen - talk incessantly, without end.

\section{Discussion}

Features of numerical symbolism and semantics of lexis and idiomology were considered on material of different languages: Zhabotinsky (1992) described cognitive and nominative aspects of numerals in modern English; Shevchenko (2001) explored the symbolism and significance of numerical components of English phraseological units; Chernevaya (2003) analyzed semantics and symbolism of numbers of Russian and Bulgarian idioms; Karasev (2005) defined cognitive dependence of numerals' meanings of English and Spanish idioms; Golubeva (2006) presented nationalcultural identity of the picture of the world in Kalmyk language in terms of cultural concepts; Kumykova (2006) investigated phraseological units of quantity and time in Kabardian language; Shondug Bayasgalan (2006) carried out comparison of the numeral semantics in phraseology of Mongolian, Russian and English languages; Osipova (2007) compared semantics and symbolism of numeric lexical units of Russian, English and French linguistic world-image; Chelnokova (2009) investigated numeral as motivational base of secondary nomination in German language; Shao Nanxi (2009) considered numerative fixed expressions in Russian language; Pasechnik (2009) conducted comparative analysis of linguocultural phraseological units with a numerical component in Russian and English languages.

Turkic linguistics considered functions of numbers in works of folklore (Gabysheva 1988 Juraev 1987, Izbekova 2000, Abdulla 2006); toponymy (Koychubayev 1969, Kudaibergenov 1980, Molchanova 1976, Murzayev 1996, Petrov 1980); phraseological units (Elesheva 1989, Gizatullina 2004); mythology (Durbilmez 2008). In recent years, numbers have become the object of attention in connection with the study of ethnocultural lexis in works of Kazakh scholars (Zhanpeisov 1989, Kaidarov 2005).

\section{Conclusion}

In conclusion, we can assert that certain numbers in worldview of many nations have sacred values. The genesis of their origin dates back to early stages of human history. The reason for their peculiar, associated with spirituality semantics cannot always be explained. However, due to the cumulative function of language and culture, fixed expressions pass down from generation to generation. At the same time, their inner form, their significance is felt even by modern representatives of a particular culture. 
Comparative analysis of sacred numbers of three languages demonstrates general and national specific in worldview of unrelated, genetically and typologically different people, their languages and culture. Comparative research of this particular group of numbers makes it possible to trace the history of formation and development of the world, comprehension of reality of a particular nation. The use of this data will certainly have an indispensable help in the translation practice.

\section{References}

Akulenko, V.V. (1990). Quantity in semantics of language. Kiev: Naukova dumka.

Gamkrelidze, T.V. \& Ivanov, V. V., (1984). Indo-European language and Indo-Europeans. V.2. Tbilisi: Publishing House of Tbilisi Univ.

Humboldt, B. (2001). Selected works on linguistics. Moscow:_Akademiya.

Husain, K.S., Islam A. (2004). Kazaksha-agylshynsha lingvomadeni sozdigi. Almaty.

Colson, J.P. (2005). Cross-linguistic phraseological studies. Conference proceedings Phraseology, Belgium: Mouton de Gruyter.

Karabayuly, A. \& Bopaiuly, B., (1998). Qazaq yrymdary. Almaty.

Kaydar, A. (2003). Thousand felicitous and figurative expressions. Astana: Bilge.

Mashanov, A. \& Bizakov, J. (1968). Bir miftik sannyn syry. Almaty.

Parkhamovich, T.V. (2011). English-Russian, Russian-English dictionary of phraseology. Moscow: Potpourri degree Language: Russian Format.

Ramstedt, G.I. (1957). Introduction to Altaic linguistics. Moscow: Publishing House of Foreign. lit.

Shevchenko, V.V. (2001). The symbolism and significance of numerical components of English phraseological units. Dis. Cand. Philology Sciences. Moscow State Pedagogical University. Moscow.

Taylor, J.R. (1989). Linguistic categorization. Prototypes in linguistic theory. Oxford: Oxford University Press.

Toporov, V.N. (1988). Numerals. Myths of the world. Moscow: Sciences.

Wierzbicka, A. (1992). Semantics, culture and cognition. Universal human concepts in culture-specific cofigurations. New York: Oxford University Press.

Zhanpeisov, E.K. (2006). Ethno-cultural lexicon of Kazakh language. Almaty. 